\title{
SISTEM PENGOLAHAN DATA DOSEN TETAP STMIK STIKOM INDONESIA BERBASIS WEBSITE
}

\author{
Ni Wayan Sumartini Saraswati ${ }^{1)}$ Eddy Hartono $^{2)}$ \\ Program Studi Teknik Informatika, STMIK STIKOM Indonesia, Denpasar, Bali \\ sumartini.saraswati@gmail.com ${ }^{1)}$ eddy_h99@yahoo.com ${ }^{2)}$
}

\begin{abstract}
This research produced the data processing web system of STMIK STIKOM Indonesia lecturer. The system will be used to assist the management in managing the data of permanent lecturers to obtain accurate information. This research use engineering method or research development method. The research starts from the stages of analysis, design to system implementation. The output of this research is a website based application, where the input of the system is the lecturer master data and lecturer history data consisting of education history, functional position history and history of grade. Output of the system is information that is needed by the management and will be visualization in reports and graphs. These graphs and reports will be used as decision support for the management STMIK STIKOM Indonesia.
\end{abstract}

Keywords: lecturer data processing system, information system, website based application.

\begin{abstract}
ABSTRAK
Penelitian ini menghasilkan rancang bangun sistem pengolahan data dosen tetap STMIK STIKOM Indonesia berbasis website. Sistem yang dibangun nantinya akan digunakan untuk membantu pihak manajemen dalam mengelola data dosen tetap sehingga diperoleh informasi yang akurat dalam tempo waktu yang singkat. Metode penelitian yang digunakan dalam penelitian ini adalah penelitian rekayasa atau metode penelitian pengembangan. Tahapan penelitian dimulai dari tahapan analisis , perancangan hingga implementasi sistem. Luaran penelitian ini berupa aplikasi berbasis website dimana input dari sistem adalah data master dosen serta data riwayat dosen yang terdiri dari riwayat pendidikan, riwayat jabatan fungsional dan riwayat kepangkatan. Output dari sistem berupa laporan dan grafik. Grafik dan laporan ini nantinya akan digunakan untuk media informasi maupun pendukung keputusan bagi pihak manajemen STMIK STIKOM Indonesia.
\end{abstract}

Kata Kunci: Sistem Pengolahan Data Dosen Tetap, Sistem Informasi, Aplikasi Berbasis Website.

\section{PENDAHULUAN}

STMIK STIKOM Indonesia sebagai institusi pendidikan yang semakin berkem-bang memiliki mahasiswa yang semakin berkembang pula dari sisi kuantitas. Untuk memenuhi rasio dosen per mahasiswa yang baik maka jumlah mahasiswa yang semakin banyak tersebut harus diikuti dengan penambahan jumlah dosen tetap. Saat ini STMIK STIKOM Indonesia memiliki 143 dosen tetap yang terdaftar dalam pangkalan data pendidikan tinggi dan tidak menutup kemungkinan jumlah tersebut akan bertambah. Manajemen dosen di STMIK STIKOM Indonesia melingkupi perekrutan dosen, pengajuan NIDN, pengurusan jabatan fungsional dosen, pengurusan kepangkatan dosen, pemeliharaan data dosen, pelatihan dosen, hingga pemberhentian ataupun perpindahan dosen. Dengan pertimbangan banyaknya jumlah dosen yang harus dikelola maka akan mengalami kesulitan ketika harus dilakukan tanpa bantuan aplikasi khusus.

Untuk saat ini manajemen data dosen tetap STMIK STIKOM tersebut hanya dibantu dengan menggunakan aplikasi Microsoft Excel. Dengan menggunakan Excel, manajemen mengalami kendala karena data hanya ada pada bagian Lembaga Pengembangan Tenaga Pendidik dan Kependidikan 
(LPTPK) sehingga ketika bagian lain ingin mendapatkan data harus mengcopy file dari bagian LPTPK. Update data dari LPTPK tidak segera diketahui oleh bagian lain sehingga data dosen yang dicopy menjadi tidak valid. Sistem online menawarkan solusi untuk masalah ini dimana data dapat diakses bersama oleh user (shareability).

Proses manajemen dosen tersebut seringkali membutuhkan data dosen yang telah terfilterisasi dari berbagai aspek dan telah diolah dalam bentuk laporan. Contohnya pada saat penyusunan borang akreditasi perguruan tinggi, pengurusan jabatan fungsional dosen, pengurusan kepangkatan dosen serta pijakan pengambilan keputusan tentang kebutuhan perekrutan dosen baru.

Berdasarkan beberapa masalah yang diuraikan di atas maka perlu dilakukan penelitian untuk merancang dan membangun aplikasi pengolahan data dosen tetap STMIK STIKOM Indonesia.

\section{TINJAUAN PUSTAKA}

\section{State of the Art Review}

Penelitian yang dilakukan oleh Akwan Sunoto dengan judul Rancang Bangun Sistem Informasi Akademik Dosen menghasilkan sistem informasi tentang biodata dan aktivitas akademik dosen sehingga pihak manajemen mendapatkan informasi valid untuk menentukan kebijakan-kebijakan yang berkaitan dengan pengembangan karir dosen dan institusi.

Penelitian ini bertujuan untuk menganalisa dan mempelajari kebutuhan informasi mengenai biodata, sebaran jenjang pendidikan, jabatan fungsional, kepangkatan, sertifikasi serta aktivitas akademik dosen bagi unsur-unsur manajemen untuk kegiatan manajerial serta menghasilkan rancang bangun sistem informasi akademik dosen yang sesuai dengan kebutuhan institusi sehingga STIKOM Dinamika Bangsa atau bagian pengembang aplikasi memiliki referensi tentang pengembangan sistem informasi akademik di STIKOM Dinamika Bangsa Jambi khususnya di pengolahan data Dosen sebagai sub sistem dari sistem informasi akademik.

Penelitian terdahulu berikutnya dilakukan oleh Intan Syahrina dan Taufik dengan judul Sistem Informasi Pengolahan Data Dosen di Universitas AlMuslim menghasilkan aplikasi sistem informasi pengolahan data dosen yang dapat memberikan output curriculum vitae (CV). Hal ini berguna untuk membantu memberikan informasi kepada pihak Universitas Almuslim ataupun mahasiswa/mahasiswi di Universitas Almuslim mengenai data dosen yang mengabdi pada Universitas tersebut juga untuk memudahkan pikah akademik dalam memanggil kembali data dosen tersebut agar dapat menunjukkan kinerjanya secara optimal.

\section{Sistem Informasi}

Menurut Jogiyanto (2005, 697-699) bahwa sistem informasi terdiri dari komponenkomponen yang disebutnya dengan istilah blok bangunan (building block). Adapun penjelasannya adalah sebagai berikut:

Blok Masukan

Input mewakili data yang masuk kedalam sistem informasi, input disini termasuk metode-metode dan media untuk menangkap data yang akan dimasukkan, yang dapat berupa dokumen-dokumen dasar.

Blok Model

Blok ini terdiri dari kombinasi prosedur, logika dan model matematik yang akan memanipulasi data input dan data yang tersimpan di basis data dengan cara yang sudah ditentukan untuk menghasilkan keluaran yang diinginkan.

Blok Keluaran

Produk dari sistem informasi adalah keluaran yang merupakan informasi yang berkualitas dan dokumentasi yang berguna untuk semua tingkatan manajemen serta semua pemakai sistem.

Blok Teknologi

Teknologi merupakan toolbox dalam sistem informasi. Teknologi digunakan untuk menerima input, menjalankan model, menyimpan dan mengakses data, menghasilkan dan mengirimkan keluaran dan membantu pengendalian dari sistem secara keseluruhan. Teknologi terdiri dari perangkat lunak (software) dan perangkat keras (hardware).

Blok Basis Data

Basis data (database) merupakan kumpulan dari data yang saling berhubungan satu dengan yang lainnya, tersimpan diperangkat keras komputer dan digunakan perangkat lunak untuk memanipulasinya. Data perlu disimpan dalam basis data untuk keperluan penyediaan informasi lebih lanjut. 


\section{Blok Kendali}

Banyak hal yang dapat merusak sistem informasi, seperti misalnya bencana alam, api, temperature, air, debu, kecurangankecurangan. Kegagalan-kegagalan sistem itu sendiri, kesalahan-kesalahan, tidak efisien, sabotase dan sebagainya. Beberapa pengendalian perlu dirancang dan diterapkan untuk meyakinkan bahwa hal-hal yang dapat merusak sistem dapat dicegah ataupun bila terlanjur terjadi kesalahan-kesalahan dapat langsung cepat diatasi.

\section{Basis Data}

Silberschatz (2002) mendefinisikan Database sebagai kumpulan data yang berisi informasi yang sesuai dengan sebuah perusahaan. Database bertujuan untuk mengatur data sehingga diperoleh kemudahan, ketepatan dan kecepatan dalam pengambilan kembali. Database Mana-gement System merupakan sekumpulan data yang saling berhubungan dan sebuah pro-gram untuk mengakses data-data tersebut.

\section{Pemrograman Berbasis Web}

Internet adalah kelompok atau kumpulan dari jutaan komputer. Penggunaan Internet memungkinkan kita untuk mendapatkan informasi dari komputer yang ada dalam kelompok tersebut dengan asumsi bahwa pemilik komputer memberikan ijin akses. Untuk mendapatkan sejumlah informasi, sekumpulan protokol harus digunakan, yaitu sekumpulan aturan yang menetapkan bagaimana suatu informasi dapat dikirim dan diterima.

Salah satu unsur yang paling umum digunakan dari Internet selain e-mail adalah World Wide Web. Dewasa ini, WWW atau yang sering juga disebut sebagai "Web" saja merupakan aplikasi Internet yang paling popular. Karena Web begitu popular, banyak orang kemudian salah mengidentikkannya dengan Internet (Simarmata, 2006).

Secara teknis, Web adalah sebuah sistem dengan informasi yang disajikan dalam bentuk teks, gambar, suara dan lain-lain yang tersimpan dalam sebuah server Web Internet yang disajikan dalam bentuk hiperteks. Informasi Web dalam bentuk umumnya ditulis dalam format HTML (Hypertext Markup Language). Informasi lainnya disajikan dalam bentuk grafis (dalam format GIF, JPG, PNG), suara (dalam format $\mathrm{AU}, \mathrm{WAV}$ ), dan objek multimedia lainnya (seperti MIDI, Shockwave, Quicktime, Movie, 3D World).
Web dapat diakses oleh perangkat lunak client Web yang disebut dengan browser. Browser membaca halaman-halaman Web yang tersimpan dalam server Web melalui protocol yang disebut HTTP (hypertext transfer protocol).

Sebagai dokumen hiperteks, dokumendokumen pada Web dapat memiliki tautan (link ) dengan dokumen lain, baik yang tersimpan dalam server Web yang sama maupun pada server Web yang lainnya. Tautan memudahkan para pengakses Web berpindah dari satu halaman ke halaman lainnya dan berkelana dari satu server ke server lain. Kegiatan penelusuran halaman Web ini biasa disebut browsing, namun ada juga yang menyebutnya surfing (berselancar).

Ada dua komponen dasar di dalam arsitektur Web, yaitu browser Web dan server Web. Browser Web menawarkan antarmuka grafis untuk pengguna dan bertanggung jawab untuk komunikasi dengan server Web. Protokol komunikasi antara browser dan server Web mengikuti protocol HTTP yang distandarisasi (Lindskog, 2003).

\section{ANALISA DAN PERANCANGAN SISTEM}

\section{Analisa Kebutuhan Sistem}

Analisa kebutuhan sistem dilakukan terhadap data yang diperoleh dengan metode wawancara dan pengamatan langsung pada bidang LPTPK yang mengelola data dosen tetap STMIK STIKOM Indonesia. Dari hasil wawancara dan pengamatan dapat disimpulkan beberapa bagian sistem yang tertuang dalam analisis kebutuhan sebagai berikut :

Input Sistem

Input sistem pada dasarnya adalah data dosen yang dibagi menjadi data master dan data transaksi. Data master adalah data pokok dosen sedangkan data transaksi adalah data riwayat pendidikan, data riwayat jabatan fungsional dan data riwayat golongan/kepangkatan.

Proses Sistem

Proses sistem dapat dibagi menjadi beberapa yaitu :

a. Input data pokok dosen

b. Update data pokok dosen

c. Penambahan riwayat pendidikan yang secara otomatis mengupdate data pendidikan tertinggi di data pokok dosen 
d. Penambahan riwayat jabatan fungsional yang secara otomatis mengupdate data jabatan terakhir di data pokok dosen

e. Penambahan riwayat golongan/kepangkatan yang secara otomatis mengupdate data golongan/kepangkatan di data pokok dosen

\section{Output Sistem}

Output yang diharapkan dari sistem dibagi menjadi laporan dan grafik antara lain :

a. Laporan data dosen keseluruhan

b. Laporan dosen yang bisa diajukan ke jabatan fungsional asisten ahli 150

c. Laporan dosen yang lulus serdos

d. Laporan dosen per pendidikan

e. Laporan dosen per prodi

f. Laporan dosen per tahun pengangkatan

g. Laporan dosen calon peserta ToT

h. Grafik dosen aktif per tahun pengangkatan

i. Grafik dosen per jenis kelamin

j. Grafik dosen lulus serdos per tahun

k. Grafik jumlah dosen per jabatan fungsional

1. Grafik jumlah dosen per golongan/pangkat

\section{Rancangan Basis Data}

Berikut adalah rancang basis data untuk aplikasi ini dalam bentuk Physical Data Model seperti ditunjukkan oleh gambar 1.

\section{Rancangan Prosedur}

Dalam menyusun rancangan prosedur pengolahan data dosen maka digunakan pemodelan berupa data flow diagram. Sebagai langkah awal dibuatlah konteks diagram yang dibutuhkan oleh aplikasi seperti ditunjukkan oleh gambar 2 .

Dari konteks diagram pada gambar 2 terlihat bahwa eksternal entitas yang terlibat adalah Admin LPTPK, Ka. LPTPK, Ketua Sekolah Tinggi, dan pegawai di bidang lainnya yang membutuhkan data. Admin LPTPK dapat melakukan penambahan, maupun pemutakhiran data dosen dalam aplikasi sedangkan eksternal entitas lainnya hanya mengkonsumsi informasi dari aplikasi dalam hal ini berupa grafik dan laporan.

Untuk penggambaran proses dalam sistem secara lebih terperinci dapat ditun-jukkan oleh data flow diagram level 0 yang diberikan oleh gambar 3

Dari gambar 3 data flow diagram dapat didefinisikan bahwa secara garis besar proses dibagi menjadi tiga yaitu pengelolaan data dosen, pengelolaan data riwayat dan pembuatan grafik dan laporan. Proses pengelolaan data dosen dan pengelolaan data riwayat sebagai input sistem sedangkan proses pembuatan grafik dan laporan sebagai output sistem. 


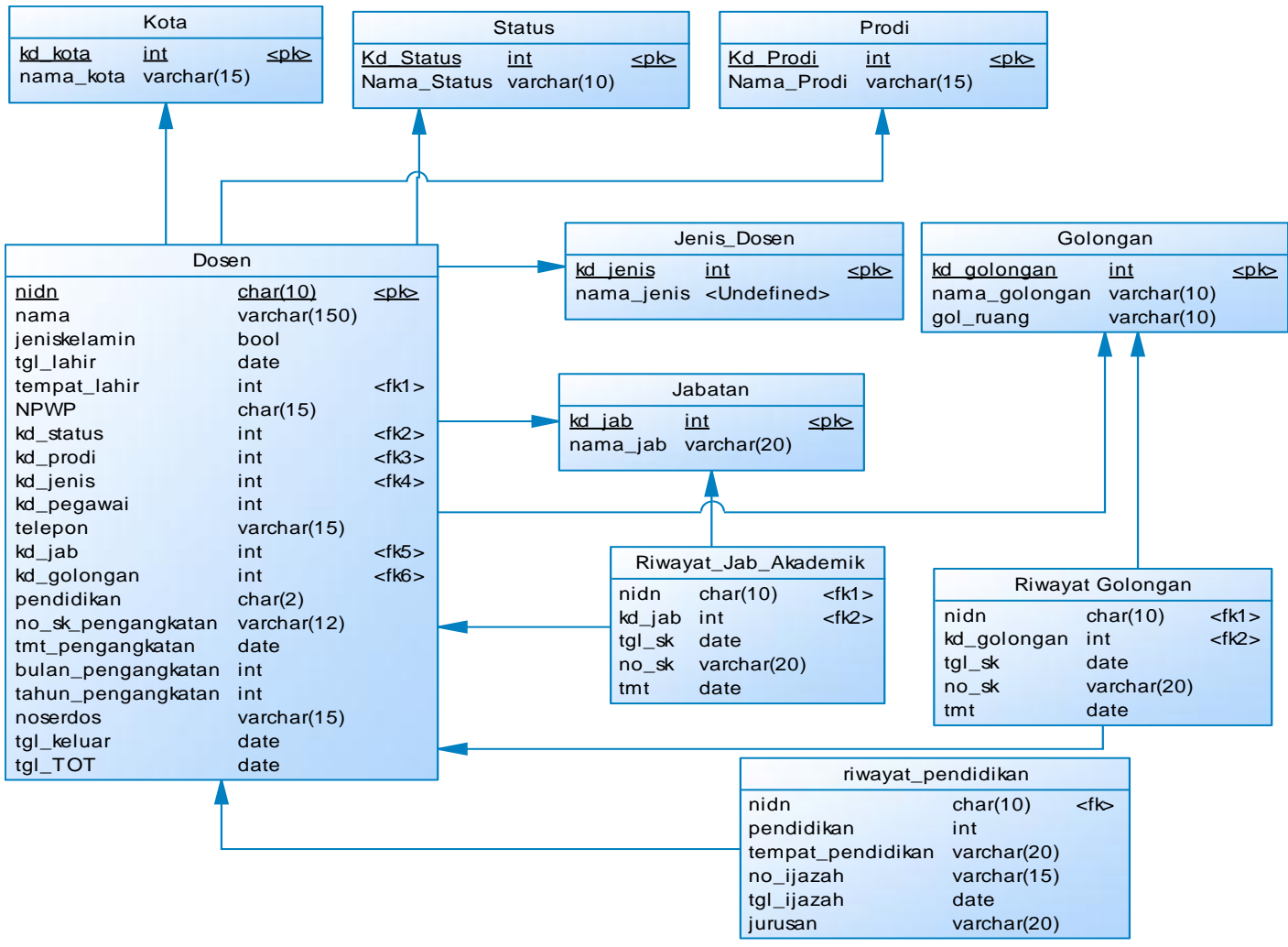

Gambar 1. Physical Data Model

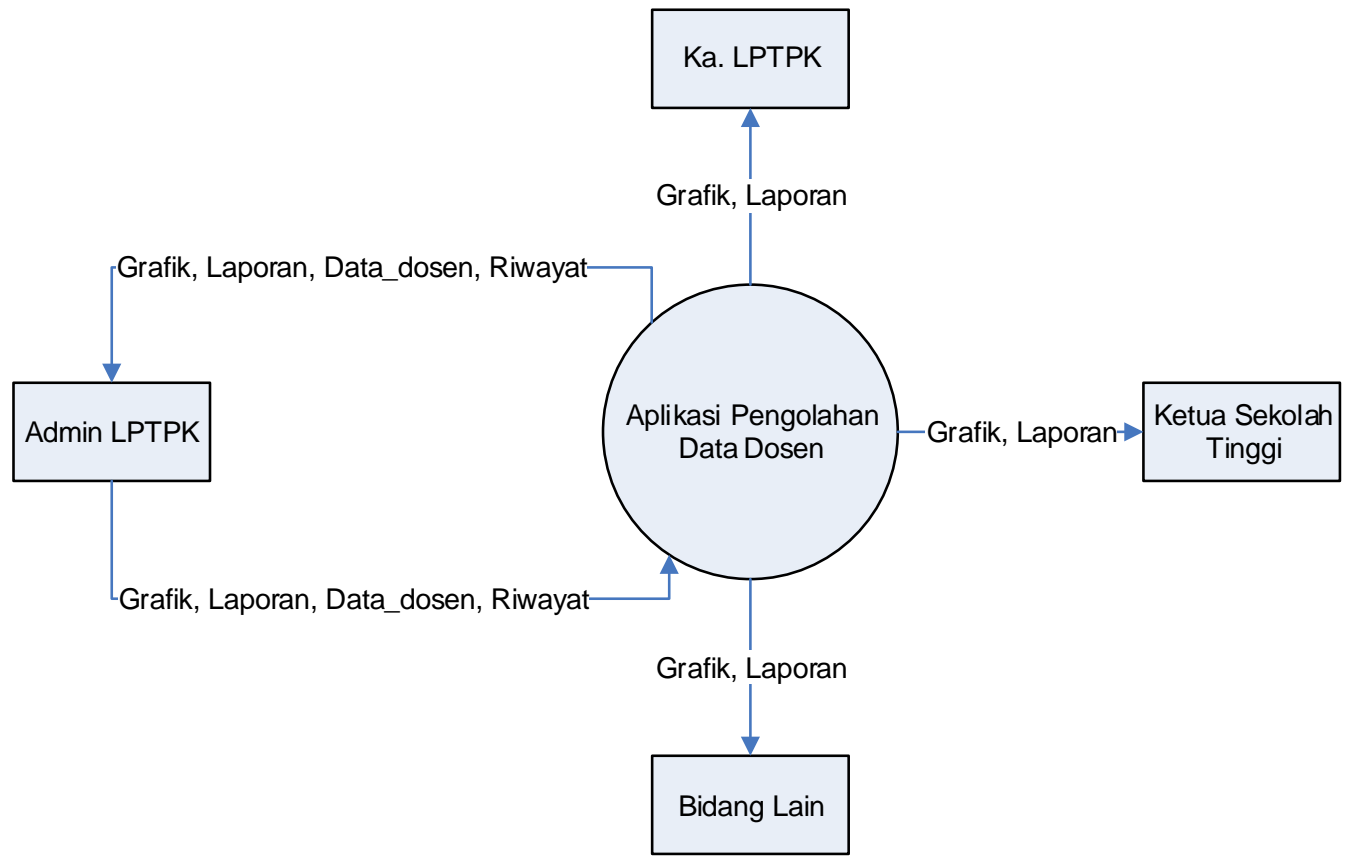

Gambar 2. Konteks Diagram Aplikasi Pengolahan Data Dosen 


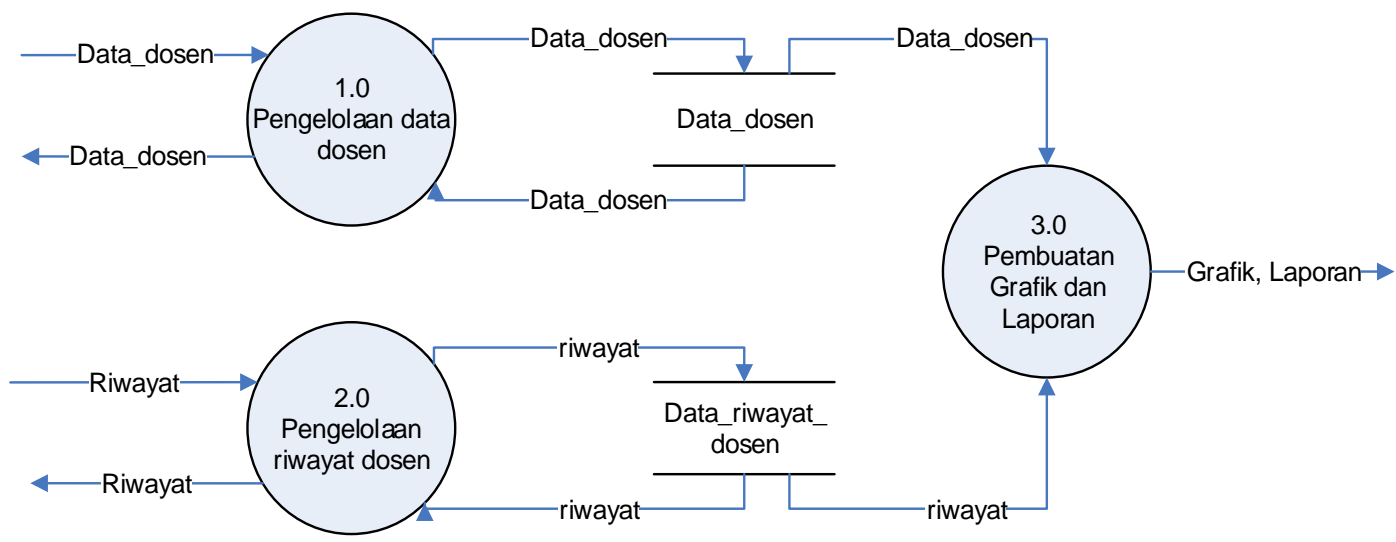

Gambar 3. Data Flow Diagram Level 0

\section{IMPLEMENTASI SISTEM}

Berikut adalah beberapa tampilan aplikasi yang telah dikembangkan. Gambar
4. menunjukkan form daftar dosen dimana pada form ini tersedia link untuk menambahkan dosen baru ataupun mengubah data dosen.

\begin{tabular}{|c|c|c|c|c|c|c|c|c|c|c|c|}
\hline \multicolumn{2}{|l|}{ SIMDOS } & \multicolumn{10}{|c|}{$\equiv$} \\
\hline Menu & & \multicolumn{10}{|c|}{ DASHBOARD > DAFTAR DOSEN } \\
\hline \& Pengaturan & $<$ & & & & & & & & & & \\
\hline \& Data Dosen & v & & & & & & & & & & \\
\hline Dosen & & \multicolumn{10}{|l|}{ Data Dosen } \\
\hline Riwayat Golongan & & \multicolumn{8}{|c|}{ Show 10 entries } & \multicolumn{2}{|l|}{ Search: } \\
\hline Riwayat Pendidikan & & NIDN & NAMA & $\downarrow \uparrow$ & Prodi & It & status & $\downarrow t$ & Telp & It & Aksi \\
\hline \& Laporan & $<$ & 0801048802 & Luh Gede Kusuma Dewi,S.E.,M.Si. & & Teknik Informatika & & Aktif & & 082236092902 & & Ubah \\
\hline \multirow{9}{*}{ \& Grafik } & $<$ & 0801108603 & Dr. I Kadek Budi Sandika, S.T., M.Pd. & & Teknik Informatika & & Aktif & & 081933069429 & & Ubah \\
\hline & & 0802078402 & I Gede Juliana Eka Putra,ST.,MT. & & Teknik Informatika & & Keluar & & & & Ubah \\
\hline & & 0803018601 & Gede Ida Agus Tapa,S.P.,M.S.M. & & Teknik Informatika & & Aktif & & 082125022379 & & Ubah \\
\hline & & 0803058801 & I Made Sunia Raharja,S.Kom.,M.cs. & & Teknik Informatika & & Keluar & & & & Ubah \\
\hline & & 0803108302 & Putu Satria Udyana Putra,S.Sn., M.Sn. & & Teknik Informatika & & Aktif & & 081916608808 & & Ubah \\
\hline & & 0803118801 & I Gde Wiradhitya Samuhata,S.E.,M.M. & & Teknik Informatika & & Aktif & & 082247484832 & & Ubah \\
\hline & & 0804018202 & Ketut Laksmi Maswari, S.P., M.M & & Teknik Informatika & & Aktif & & 08123645849 & & Ubah \\
\hline & & 0804038504 & Desak Putu Diah Kumala Dewi,S.E.,M.M. & & Teknik Informatika & & Aktif & & & & Ubah \\
\hline & & 0804068401 & Komang Suwilindiari, S.Sn., M.Si & & Teknik Informatika & & Keluar & & & & Ubah \\
\hline
\end{tabular}

Gambar 4. Form Daftar Dosen 


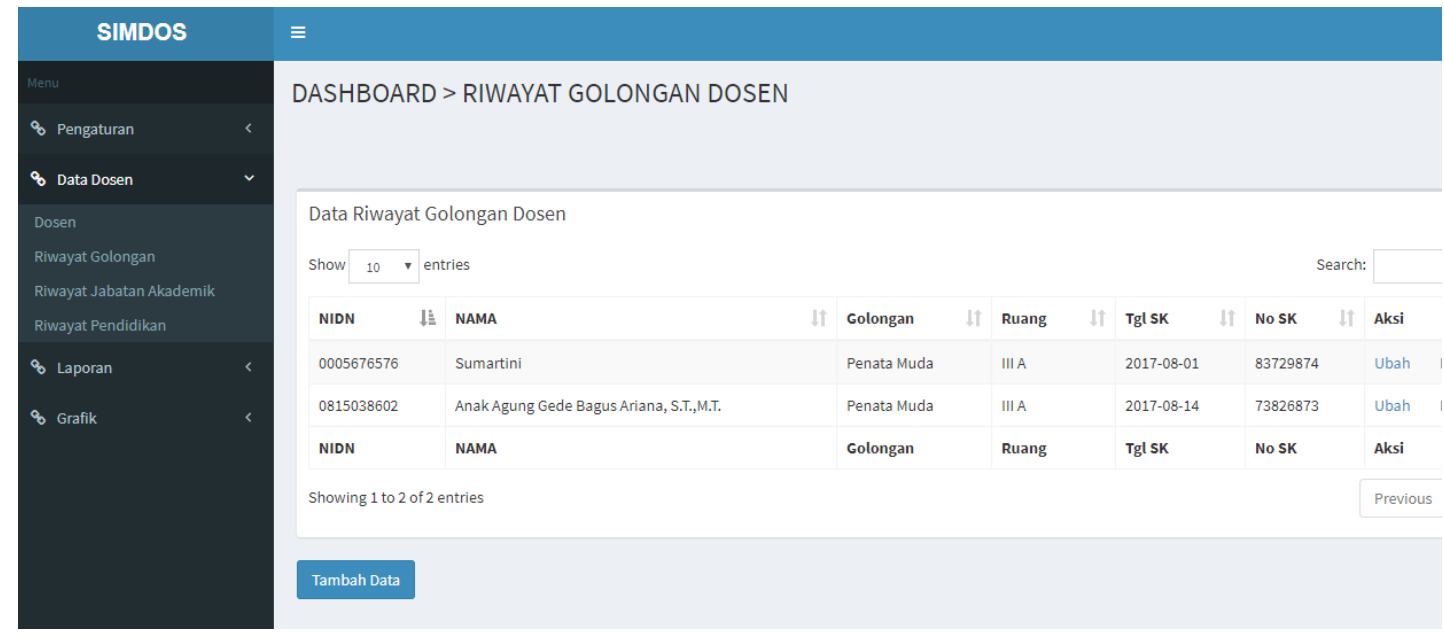

Gambar 5. Form Riwayat Golongan Dosen

Gambar 5. Menunjukkan dialog antar muka untuk menambahkan maupun mengubah riwayat kepangkatan atau golongan dari dosen. Form yang identik juga digunakan untuk manajemen riwayat pendidikan dosen dan riwayat jabatan fungsional dosen.

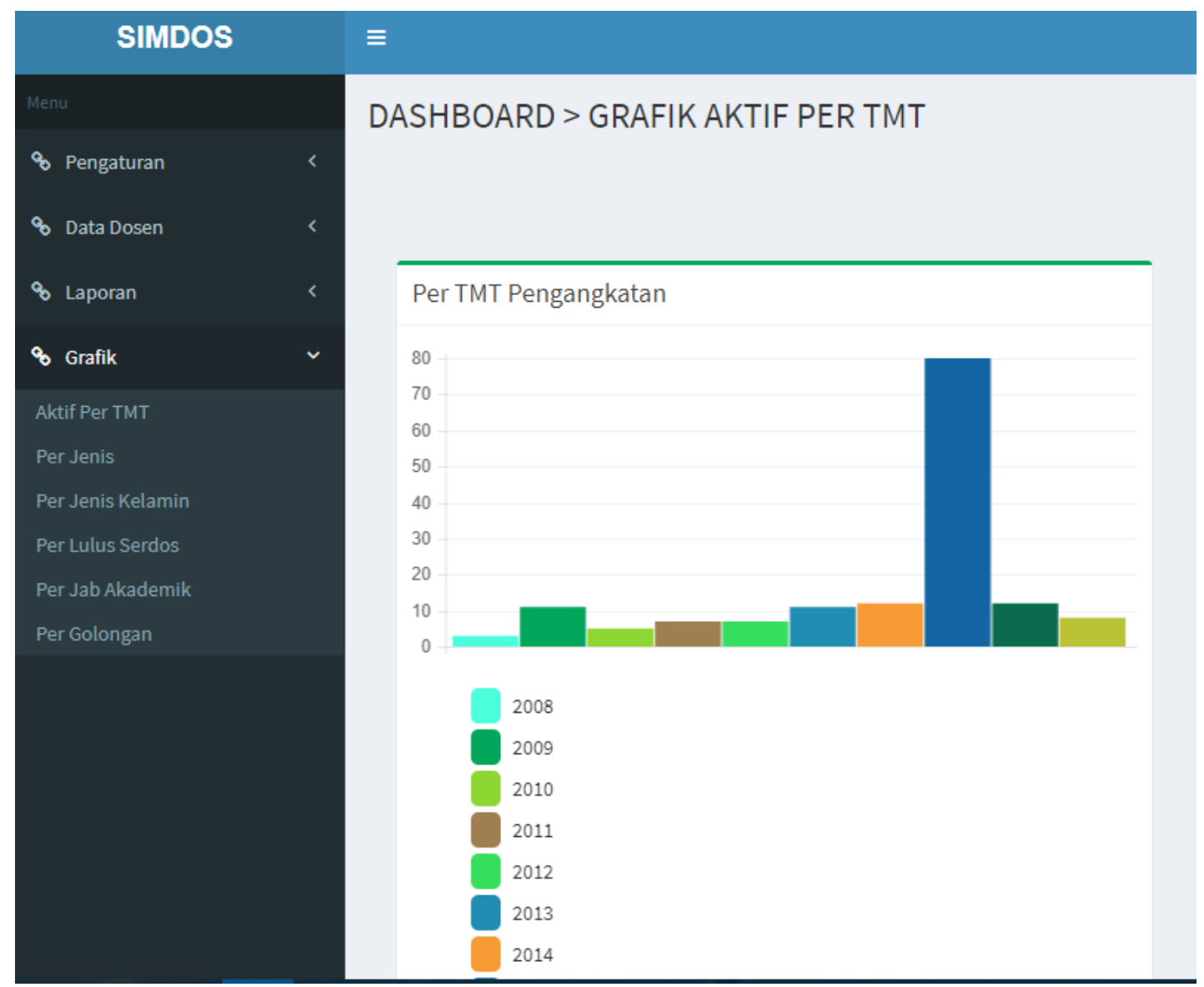

Gambar 6. Form Grafik Dosen per tahun

Gambar 6 menunjukkan contoh grafik yang dihasilkan oleh aplikasi. Gambar 6 adalah grafik jumlah dosen yang diangkat pada STMIK STIKOM Indonesia per tahunnya. 


\section{SIMPULAN}

Adapun kesimpulan yang didapatkan dari penelitian ini adalah :

Kebutuhan fungsional sistem secara garis besar terbagi menjadi pengelolaan data dosen, pengelolaan data riwayat dosen, dan pembuatan grafik dan laporan.

Pemutakhiran data riwayat dosen akan secara otomatis memutakhirkan data dosen.

User sistem terbagi menjadi admin LPTPK, Kepala LPTPK, Ketua Sekolah Tin

ggi dan bidang lainnya yang memerlukan data.

Grafik yang dihasilkan adalah grafik jumlah dosen per tahun pengangkatan, jumlah dosen per jenis kelamin, jumlah dosen per dosen ps/non ps, jumlah dosen per tahun lulus serdos, jumlah dosen aktif per golongan ruang, jumlah dosen aktif per jabatan fungsional.

Laporan yang dihasilkan adalah laporan dosen yang lulus serdos, dosen yang siap diajukan ke asisten ahli, dosen per pendidikan, dosen per prodi, dosen per tahun pengangkatan, dan dosen yang telah mengikuti Training of Trainers.

\section{DAFTAR PUSTAKA}

[1] Abdul Kadir, 2008. Dasar Pemrograman Web Dinamis menggunakan PHP. Bandung : ANDI OFFSET.

[2] Akwan Sunoto,-. Rancang Bangun Sistem Informasi Akademik Dosen.-

[3] A,O'Brien, James. (2003).Introduction to Information System Essential for EBusiness Enterprise Eleventh Edition. New York : McGraw-Hill.

[4] Budi Raharjo, dkk 2010. Modul Pemrograman Web (HTML, PHP, \& $M Y S Q L)$. Bandung : Modula.

[5] Etta Mamang Sangadji \& Sopiah, 2010. Metodologi Penelitian Pendekatan Praktis dalam Penelitian. Bandung : ANDI OFFSET.

[6] Fathansyah, 2015. Basis Data. Bandung : Penerbit Informatika.

[7] Gordon B. Davis \& Margrethe. H Olson, 1984; Management Information System : Conceptual Foundation Structure and Development, International Edition McGraw-Hill, Singapore.

[8] Janner Simarmata, 2006. Pemrograman WAP dengan menggunakan WML. Yogyakarta : Penerbit ANDI.

[9] Janner Simarmata, 2009. Rekayasa Web. Bandung : ANDI OFFSET.

[10] Kendall \& Kendall, 2011. Systems Analysis and Design. Prentice Hall.

[11] Lindskog, Helena \& Stefan Lindskog, 2003. Web Site Privacy with P3P. Canada.

[12] MADCOMS, 2008. Teknik Mudah Membangun Website dengan HTML, PHP \& $M Y S Q L$. Bandung : ANDI OFFSET. 